\title{
Pós-História e Pós-Modernidade. Dois conceitos-chave da filosofia da cultura crítica de Vilém Flusser e sua análise contemporânea da mídia e das imagens técnicas
}

\author{
Michael Manfred Hanke
}

Resumo: Vilém Flusser ficou conhecido pelo conceito de pós-história, utilizado pela primeira vez em 1967, intitulando um livro de 1982. A pós-história de Flusser não é idêntica ao conceito de pós-modernidade, desenvolvido, em 1979, por Jean-François Lyotard, que fez carreira a partir do início dos anos de 1980. Entretanto, em 1985, após visitar a exposição inaugural do Centre Pompidou em Paris sobre as novas tecnologias, organizado por Lyotard, Flusser se apropriou do conceito de pós-modernidade. Publicou até três artigos sobre o assunto que, porém, não receberam a devida atenção. A relevância para a comunicação cresce pelo fato de que Lyotard, na sua exposição, utilizou a famosa fórmula de Lasswell como princípio organizador - Who says what in which channel to whom with what effect? A reflexão dada por Flusser sobre as novas tecnologias ganha assim uma nova contextualização teórica.

Palavras-chave: pós-história; pós-modernidade; Vilém Flusser; imagens técnicas.

Abstract: Post-history and postmodernity. Two key philosophical concepts of critical culture and of contemporary analysis of media and of technical images by Vilém Flusser - Vilém Flusser's well-known concept of pós-história (post-history), used for the first time in 1967 and benaming a book from 1982, is not identical with postmodernity, the concept developed by Jean-François Lyotard in 1979, that became quite popular in the early eighties. Nevertheless, after visiting the inaugural exposition of the Centre Pompidou in Paris in 1985 on new technologies, organized by Lyotard, Flusser integrated the concept of postmodernity into his theory. The three published articles on the topic did not receive propper attention. 
The relevance for communication theory is also provided by the fact that Lyotard's exhibition, as an underlying structure, made use of Lasswell's famous formula (Who says what in which channel to whom with what effect?). This enriches Flusser's reflections on new technologies by an additional aspect.

Key-words: post-history; postmodernity; Vilém Flusser; techno-images.

\section{Introdução}

São conhecidas, para quem a obra é familiar, as fases nas quais Vilém Flusser divide o percurso da cultura humana: pré-história, história e pós-história. Com esse esquema, e parafraseando Hegel, Flusser (1986, p. 1) quer captar "a fenomenologia do espírito ocidental", como escreve em "Texto/imagem enquanto dinâmica do Ocidente" (ibid.). Quatro eventos são considerados cruciais para essa história: as primeiras imagens, os primeiros textos, os primeiros impressos e as primeiras fotografias.

Eles articulam a imaginação, a conceituação, a conceituação dominando a imaginação e uma "imaginação nova, com consequências ainda imprevisíveis" (ibid., p. 1). Essa escalada em forma de hipótese começa com as imagens rupestres de Lascaux (há 20 mil anos), passa pelos primeiros textos alfabéticos (em torno de 2.500 a.C.), os primeiros impressos (em torno de 1.500) e pela primeira fotografia (em torno da metade do séc. XIX) "para avançar e perder-se nas brumas de um futuro imprevisível" (ibid.)1. Esses trechos são denominados por Flusser da seguinte maneira:

O que mede entre Lascaux e os textos poderá ser chamado "pré-histórica", o que parte da fotografia rumo a aventura poderá ser chamado "pós-história", e o trecho central, que vai dos textos até as fotografias, tendo os impressos como ponto central, poderá ser chamado "história no sentido exato do termo" (Ibid.).

Podemos afirmar, juntamente com Andreas Ströhl - em sua tese de doutorado que, toda obra de Flusser encara a transição epocal (den epochalen Übergang) de uma cultura de pensamento linear, baseada na escrita, implicando crítica e historicidade para formas de comunicação relativamente novas de imagens técnicas e de códigos digitais (STRÖHL, 2009, p. 1; 17). E é nesse sentido que Flusser (1973) resume o raciocínio de outro texto de importância fundamental, "Line and Surface", de 1973 - em português, "Linha e Superfície" (2007, p. 101-125) - dizendo que:

1 Flusser apresenta várias formas dessa história da humanidade. Segundo uma delas, escrita em 1991 (FLUSSER, 1993, p. 254-262), faz 40 mil anos a inovação de fazer imagens (rupestres), 7 mil anos a da escrita linear, 3.500 a do alfabeto e, depois da imprensa, estamos hoje na fase do cálculo e da computação (ibid., p. 262). 
a nossa cultura oferece dois tipos de mídia que medeiam entre nós e o mundo de fatos: as lineares, como a escrita; e as de superfícies, como as imagens. O primeiro tipo concebe os fatos como processos, em ordem sucessiva, historicamente (historical successions). O segundo, em cenas. Um terceiro tipo, imagens em movimento (filme, TV), apareceu recentemente. Ele compartilha aspectos da mediação linear e cênica, se torna atualmente dominante e será um fator decisivo no futuro. Em caso de abandono da linearidade, deixa também a característica clara et distincta do pensamento linear, o que caracteriza uma sociedade pré-histórica (a pre-historical society). Caso essa nova forma consiga integrar a linearidade na superfície, assistiremos ao surgimento de uma sociedade pós-histórica. Ela teria uma imaginação estruturalista de conceitos científicos, estéticos e políticos (FLUSSER, 1973, p. 1216).

"Estruturalista", nesse caso, significa desenvolver diferentes e alternativos cenários, o que implica escolher racionalmente entre eles, fazendo história em vez de ser submetido a ela. Enquanto o pensamento pré-histórico não dispõe da linearidade nem é clara et distincta - expressão cartesiana que Flusser usa constantemente - o pensamento histórico segue essa lógica e o pensamento pós-histórico (possivelmente) avança unificando as conquistas da linearidade e das imagens, um tipo de aproveitamento lógico das imagens.

Segundo Flusser, cada uma das três fases tem seu próprio estilo de "estar no mundo", ou seja, uma existência (Dasein) mítica, histórica e pós-histórica. Essa ideia se encontra articulada no título, bem como no corpo do artigo Mythisches, geschichtliches und nachgeschichtliches Dasein (1993). A lógica dessa divisão segue o desenvolvimento da mídia pela cultura humana, iniciando-se com a marca inicial da fase da história: a escrita. A sua introdução representa uma primeira revolução da mídia, sendo ela responsável por uma série de conquistas que destacam, segundo Flusser, essa fase da história: a ciência, a lógica, o pensamento causa-efeito, tudo resumido como pensamento linear.

A fase anterior, pré-histórica, ainda não dispõe dessas conquistas e é marcada por um pensamento chamado mágico-imagético, circular. Por sua vez, o que marca o fim da história e o início da pós-história é o fim da escrita, o que implica também o fim da cultura baseada nela. Em seguida, iniciou-se uma nova fase da segunda revolução midiática, "pós-histórica", conceito-chave para Flusser. O autor é visto como o filósofo da fotografia - sem dúvida, uma verdade - tendo em vista o fato de o seu livro Ensaio sobre a fotografia - para uma filosofia da técnica ser o seu trabalho mais conhecido, mais traduzido e mais divulgado.

O interesse pela fotografia mostra logo que esta é a primeira mídia, a que inaugurou um novo paradigma: o de novas mídias e das imagens técnicas. Como destaca Santaella, que vê Flusser como "pensador da pós-modernidade" (2000, p. 124) avant la lettre: "A visão ontológica da fotografia como paradigma de todos os tipos e formas de aparelhos", e "como modelo pós-industrial de todos os aparelhos", "é sem dúvida o aspecto de maior originalidade do pensamento de Flusser" (ibid., p. 129). 
Essa nova fase "pós-histórica" é marcada pela mudança radical, provocada pela revolução da informação e da comunicação, sendo que: "(1) Não é mais a posse, mas a informação (não mais o hardware, mas o software) que proporciona poder; e (2) não é mais a economia, mas a comunicação que constitui a infraestrutura da comunidade e da sociedade" (FLUSSER, 1999, p. 155). Essa mudança é que caracteriza o novo "mundo pós-moderno": a moral do trabalho vai sendo substituída pela moral informativa (FLUSSER, 1988, p. 1).

Para Flusser, essa "reviravolta de valores" é consequência da revolução industrial e dos seus impactos sobre a antropologia: a revolução industrial mostrou que o trabalho é mecanizável; pode ser mais bem executado por máquinas; que máquinas o executam melhor que homens; e que trabalho é "um gesto indigno do homem" (ibid., p. 1). Essas máquinas podem ser programadas e "programá-las é um gesto caracteristicamente humano" (ibid.). E programar significa:

[...] manipular símbolos segundo regras. Uma das distinções da pós-modernidade é, pois, que, pela primeira vez na história, o homem se assume ente cuja dignidade específica é a manipulação de símbolos, (a codificação), que confirmam significados ao mundo, (tido por absurdo), e à vida humana, (tida por absurda). Que o homem se assuma "homo ludens", e não mais "homo faber". (lbid., p. 1)

Assim, a transição da modernidade (der Moderne) para a pós-modernidade é acompanhada por uma mudança de códigos. Na modernidade, quando o próprio homem trabalhava, ele se comunicava com outros homens diretamente ou através dos meios (Medien), porém, na época pós-moderna, ao se comunicar com máquinas, é indispensável o desenvolvimento de "códigos claros e distintos", códigos novos, digitais:

O novo clima existencial pós-histórico [...] se manifesta em muitas formas, por exemplo, como estruturalismo cibernético, politologia baseada em cenários, ou transideologização. Deve ser observado concretamente nos programas impressos nas memórias dos computadores, ferramentas inteligentes e microprocessadores ${ }^{2}$ (FLUSSER, 2010a, p. 115).

Apesar dessa nova fase, ainda estamos vivendo em condições anteriores, ou seja, "nos níveis mágico-mítico e histórico. Deciframos programas de TV como se eles fossem imagens tradicionais ou textos lineares, contando narrativas" ${ }^{\prime 3}$ (Ibid.). Até conseguirmos desenvolver uma imaginação adequada para essa nova forma de cultura, somos condenados a ser dominados pelo apparatus-operator complex, o complexo operado por aparelhos, que caracteriza a pós-história (da cultura das imagens técnicas).

2 Do inglês: "the new posthistorical existential climate which characterises the tecnoimage culture articulates itself in many ways, for instance in structuralism, cybernetics, scenario-based politology, or trans-ideologisation. It may be concretely observed in the programs impressed into the memories of computers, intelligent tools, and miniprocessors".

3 Do inglês: "on the magico-mythical and on the historical level. We deciver, all of us, TV programmes as if they were traditional images or as if they were linear texts telling some story". 
Flusser, porém, além dos meios, também reflete sobre as condições da modernidade. Repetidamente, insiste que, depois de Auschwitz e Hiroshima, a modernidade cunhada pelo projeto do humanismo e iluminismo acabou (1994, p. 15). Assim, o conceito da pós-modernidade de Flusser é utilizado para marcar um ponto teórico central: a nova sociedade, telemática, considerada uma moldura antropológica para o novo homem. Estamos no rumo de uma nova época, "a idade eletromagnética", marcada por "palavras-chave como microeletrônica, inteligência artificial, robótica, imagem de computador e holograma", que "são algumas das indicações neste caminho íngreme da nossa cultura material para a cultura imaterial", na qual "não vamos mais trabalhar com material lento, mas com raios e fragmentos de raios" (FLUSSER, [19--b], p. 1).

Estamos entrando numa nova sociedade pós-histórica, caracterizada por máquinas que calculam e computam, resultado de um processo, no final do qual o código numérico (digital) se separa do código alfanumérico (composto por alfabeto e números) e se torna o único código vigente: "Novas formas, de sociedade e de consciência, estão emergindo graças ao abandono do código alfanumérico pelas cifras. Pós-história é isto" (FLUSSER, 1998b, p. 191). Esse processo pode ser considerado uma revolução (midiática ou de comunicação?).

Flusser, discutindo a pergunta numa carta a Milton Vargas (17 de fevereiro de 1974), considera o termo já "gasto", como há "revolução no mercado dos refrigerantes", mas defende que há uma definição aceita por consenso relativamente geral: revolução seria uma "subversão da ordem da sociedade em todos os níveis, desde o econômico, passando pelo tecnológico, social, político, científico, artístico, cultural, normativo, filosófico até o religioso" (FLUSSER, 1974, p. 1). Embora sendo localizável, é um "processo universal" e "modifica o estar-no-mundo humano" (ibid.). O termo "revolução", assim, parece adequado às transformações midiáticas atuais, numa fase posterior a uma ordem antiga.

Evidentemente, pós-história, conceito usado por Flusser, não é o mesmo que pós-moderno. Entretanto, o pós-histórico não defende só uma mudança de meios, mas também da estrutura do nosso conhecimento. Essa mudança é expressa pelo conceito de pós-modernismo de Lyotard.

\section{Pós-modernidade}

O termo pós-modernidade, infelizmente, apresenta uma série de problemas terminológicos. Ele tem, segundo Welsch (2008, p. 14-37), pelo menos quatro sentidos diferentes, relacionados à crítica literária, arquitetura, pintura, sociologia e ao sentido filosófico cunhado por Lyotard.

Em Flusser, o conceito de pós-história é utilizado em toda a sua obra, de 1967 até 1991 (na última palestra, Paradigmenwechsel). É um conceito-chave, utilizado em três sentidos:

1. o termo pós-história, sem referência ao conceito de pós-modernidade;

2. o uso dos termos pós-histórico e pós-moderno como sinônimos (das gegenwärtige 
Sprechen von Postmoderne und/oder Nachgeschichte) (1991b, p. 31);

3. o uso do termo posthistoire, respectivamente pós-moderno, no sentido de Lyotard e com referência a este autor.

Cedo, em 1966, Flusser (1993, p. 138), refletindo sobre a história da nossa cultura, defende que houve uma ruptura na corrente da história que se iniciou durante o século XIX, mas somente se manifestou na década de 1940, com uma profunda diferença qualitativa, o que cria um abismo entre as duas épocas. Ele destaca os projetos exemplares de energia nuclear, do computador e do foguete (ibid., p. 132) como projetos culturais que o homem desenvolveu diante do vazio da natureza.

No fundo, ele observa uma mudança radical da nossa realidade (ibid., p. 134), inclusive do tempo, do espaço, da energia, tudo acompanhado por um esgotamento da ideia de progresso. E, de acordo com esse diagnóstico da "futilidade da história" (ibid., p. 137), já em 1967, conclui que a pós-história está chegando. ${ }^{4}$

Depois da transição da sociedade agrária para a sociedade industrial, estamos agora na fase de transição para a sociedade pós-industrial (ibid., p. 28), baseada na tecnologia, informação e computação. As categorias históricas, no decorrer dessa transição, deveriam ser abandonadas e substituídas por aquelas da teoria da informação e cibernética (ibid., p. 180-181). Essa transformação é revolucionária no sentido de mudar o mundo da vida (Lebenswelt) e o sujeito descrito em "pós-história", atuando nele profundamente (FLUSSER, 1982 (2011); 1993). Flusser, mais tarde, preserva o mesmo esquema, substituindo apenas os exemplos citados pela fotografia.

\section{Flusser e Lyotard}

Em pelo menos cinco textos (três artigos publicados e dois manuscritos), Flusser se refere explicitamente ao conceito de pós-modernidade de Lyotard (FLUSSER 1987a, 1987b, 1989, [19--]b, [19--]e); em outros se refere à pós-modernidade (Nach der Post-moderne? (1993, p. 303-325)) sem fazer referência a Lyotard.

Esse conceito, completamente diferente daqueles da arquitetura e da literatura, baseado no conceito de jogos da linguagem de Wittgenstein, tenta analisar a mudança radical causada pelas tecnologias telemáticas e da informação (LYOTARD, 2009, p. 33) da sociedade no final do séc. XX. Lyotard chega à constatação do fim das grandes narrativas, especificamente dos projetos de iluminismo e idealismo.

Assim, citando Lyotard ou não, existem coincidências entre os dois: Flusser baseia-se também reiteradamente nos jogos de linguagem wittgensteiniana e analisa a crise contemporânea da sociedade, causada pela transformação desta pelas novas tecnologias

4 "Die Posthistorie, die Nachgeschichte meldet sich an. [...] unsere Zukunft ist nachgeschichtlich" (FLUSSER, 1993, p. 142). 
em termos da sociedade "telemática" - o termo, de S. Nora/A. Minc de 1979, é utilizado por Flusser assim como várias vezes por Lyotard em seu livro (1979). E Flusser também declara, não só ocasionalmente, o fim do projeto de humanismo e do iluminismo. Logo, existem afinidades sistemáticas entre os dois.

O livro de Lyotard, publicado em 1979, rapidamente alcançou sucesso internacional e se destacou na discussão da época. Não se sabe quando Flusser tomou conhecimento da discussão, mas, certamente, o mais tardar em 1985. Nesse ano, Lyotard foi curador da exposição inaugural do Centre Pompidou, intitulada Les Immatériaux. ${ }^{5}$ Flusser já tinha desenvolvido interesse pelas imagens técnicas pelo menos desde 1973 - quando participou de um congresso sobre esse tema em Paris - e, por morar na França, não deu para não tomar conhecimento desse evento tão marcante cujo tema foi "a imaterialidade dos meios eletrônicos e do mundo técnico" (WEIBEL, 1985, p. 29; tradução do autor).

Nas palavras de Flusser, a exibição de Lyotard "quis mostrar como seria a sociedade futura, moldada pela informação pura"6 ([19--]e, p. 6; tradução do autor): "Não havia objeto presente, somente informação imaterial", "informação inútil (...) do ponto de vista da cultura industrial"7. Porém, essa inutilidade da informação imaterial não vale para a cultura futura da sociedade pós-industrial:

Mudando o ponto de vista, a exibição sugere que é exatamente essa inutilidade da informação pura que vai permitir ao homem uma vida cheia de significados pela primeira vez na história. Os filósofos antigos vislumbravam o conceito do "ócio" (schole), que é a finalidade do toda ação (a-scholia). Graças aos autômatos, o homem se torna desempregado, e assim libertado para a elaboração dialógica e desnecessária de informação pura. Isso é chamado de lúdico, e a revolução cultural atual pode ser vista como uma mutação do "homo faber" para o "homo ludens". Todo o trabalho pesado será delegado para aparatos, e o novo homem irá jogar, e rememorar com desprezo a seriedade animal das gerações do passado. ${ }^{8}$ (FLUSSER, [19--]e, p. 6-7).

Ou seja, Flusser projeta toda sua teoria sobre o futuro universo das imagens técnicas, dos novos objetos culturais da sociedade pós-industrial, do novo homem e da revolução cultural causada pela informação imaterial (= digital) na exibição de Lyotard, utilizando-

5 Veja também o texto de Lyotard traduzido por Gumbrecht para o alemão e publicado na coletânea Materialität der Kommunikation de Gumbrecht e Pfeiffer (LYOTARD, 1988).

6 Do inglês: "wanted to show how the future society of pure information will look like".

7 Do ingles: "There was no object present, just immaterial information", "useless information (...) from the point of view of industrial culture".

8 Do inglês: "if one changes one's point of view, the exhibition suggests that it is precisely this uselessness of pure information which will permit man to lead a meaningful life for the first time ever. The ancients thought of idleness, ("schole"), that it is the purpose of all action, ("a-scholia"). Thanks to the automats man is becoming unemployed, and thus free for useless dialogical elaboration of pure information. This is of course called "play", and the present cultural revolution may be seen as a mutation from "homo faber" into "homo ludens". All serious business will be relegated to apparatus, and the New Man will play his games, and look back with contempt on the animal seriousness of past generations". 
o como matriz de pensamento. Ele pensa a comunicação sob a pré-condição da imaterialidade digital. "Les Immatériaux", para Flusser, são idênticos aos "softwares", "símbolos moles" ou manipuláveis, e à computação de "informação pura" (1987a, p. 18; 1989, p. 4-5).

O conceito da exposição Les Immatériaux (1985) e a adaptação da fórmula de Lasswell "Quem fala o que, para quem, em qual canal, com qual resultado?"” (1948), por Lyotard, é reproduzido por Flusser na publicação sobre a matéria em 1987 (FLUSSER, 1987a, p. 17). Segundo esse modelo, na ciência, na técnica e na arte pós-moderna será o conceito de "informação" que irá ocupar o centro do interesse científico, marginalizando o conceito de "objeto" (FLUSSER, 1998b, p. 6).

\section{Concepção}

$\underline{\text { oprincipio }}$

A partir da raiz mat, selecionamos os cinco termos:

- Material de base (no sentido de suporte material, substância que garante a materialidade de alguma coisa);

- Material (equipamento ou conjunto de instrumentos usados em uma atividade ou serviço)

- Maternidade

- Matéria (no sentido de assunto ou tema)

- Matriz

Distribuímo-los sobre a estrutura operatória:

- O material de base é o suporte da mensagem (Jornal? Revista? Folder?);

- O material é o que garante a apropriação, a transmissão e a captura/compreensão/recepção da mensagem;

- A maternidade designa a função do emissor da mensagem;

- A matéria da mensagem é seu referente (o assunto de que se fala);

- A matriz é o código da mensagem.

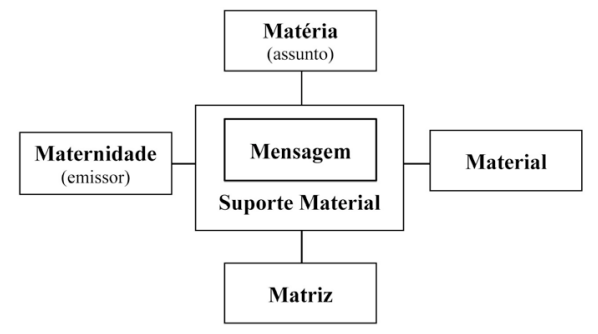

Na nomenclatura de Lasswell:

- Material de base ou suporte material = por meio de quê isto fala?

- Material = para quê (finalidade) isto fala?

- Maternidade $=$ em nome de quê isto fala?

- Matéria = sobre o quê isto fala?

- Matriz = em quê isto fala?

(isto $=$ mensagem; significado $=$ o que isto $\mathrm{diz})$

(Tradução livre por Tâmara Abreu, UFRN, Natal).

Fig. 1. Conceito da exposição Les Immatériaux de J.-F. Lyotard, reproduzido por Flusser, em francês, e aqui traduzido para o português.

9 Do inglês: "Who says what in which channel to whom with what effect?". 
Uma esperança que Flusser tem e apresenta reiteradamente é que o futuro irá "romper a barreira entre ciência e arte"; a "técnica seria novamente sinônimo de arte, como o foi antes da Idade Moderna" e a "tecnologia será sinônimo de estética", o que desarmaria o perigo da tecnocracia (1998, p. 175). E o ponto central da exposição Les Immatériaux, segundo Flusser, é provar que no futuro, "na chamada pós-modernidade", qualquer tentativa de distinção entre o engajamento científico e o artístico será condenada ao fracasso (1987a, p. 16).

Ele defende a reversão da separação entre techne e ars, e considera essa reviravolta um progresso esperado da nova época: "O impacto da exposição, (seja ela ou não bem sucedida na sua intenção de servir de introdução para a cultura pós-moderna), reside no fato de ter borrado as fronteiras entre ciência e arte" (1989, p. 1). E: "Se podemos confiar na exposição de Lyotard, e a pós-modernidade realmente vai superar a ruptura entre ciência e arte, e se 'técnica' e 'arte' novamente seriam sinônimas, não precisaremos sentir saudades da modernidade" (1987a: 17-18; tradução do autor).

Em suma, Lyotard e Flusser explicam o progresso da telemática pós-moderna numa forma similar:

1. consta o fim das grandes narrativas (Lyotard: iluminismo, idealismo; Flusser: iluminismo, progresso burguês e socialista);

2. a lógica informacional, vinda das ciências exatas, toma conta da cena cultural e preenche o vácuo que a cultura moderna deixou.

\section{Flusser e Vargas}

O artigo "Do Sanduíche: uma consideração pós-moderna" (FLUSSER, 1987b) foi publicado em conjunto com Flusser (1987a), ou seja, o conceito da pós-modernidade utilizado nas duas publicações é idêntico. A frase "O caos é ordem ainda não revelada, e ordem é caos ainda não revelado"10 quer dizer, segundo Flusser, que abaixo de um fenômeno aparentemente caótico - neve, por exemplo - existe uma organização ordenada (leis fractais), e que debaixo de uma ordem se encontra uma estrutura caótica.

Desse modo, o mundo é estruturado em níveis de ordem e caos, um acima do outro, como um sanduíche. Somos, assim, obrigados a desistir da ideia da ciência moderna como método do caos em direção à ordem de uma mathesis universalis (1987b, p. 20). Ela toma mais o caráter de uma projeção do que de descobertas ou revelações e, portanto, se aproxima do procedimento da arte. A cultura pós-moderna do futuro irá - essa é a expectativa de Flusser - reunir novamente a ciência (técnico-científica) e a sua função de "descobrir" com a arte e a sua função de "inventar", separadas desde a época do Renascimento e do Barroco (1987b, p. 20).

10 Em alemão: "Chaos ist unentdeckte Ordnung, und Ordnung ist unentdecktes Chaos" (1987b, p. 19). 
A perspectiva pós-moderna, segundo Flusser, não diferencia fundamentalmente obra de arte de teoria científica; as duas fornecem conhecimento e uma verdade; conceito, no entanto, que carece de uma redefinição nesse novo contexto (1987b, p. 21). Dessa maneira, relativizando as fontes do conhecimento - e negando à ciência o privilégio do método único da racionalidade - e defendendo a "equivalência e complementaridade do conhecimento científico e artístico" (1998a, p. 171), Flusser se encaixa na corrente dos pensadores pós-modernos (AYLESWORTH, 2010, p. 1).

Num esboço, intitulado Pós-moderno para o simpósio Laboratório do Futuro, de 1990, e homenageado por seu amigo Milton Vargas, Flusser utiliza argumentos semelhantes para versar sobre "a insistente discussão atual sobre a pós-modernidade" (1990, p. 1). Discussão que “impõe, nem tanto a reflexão sobre o que seja 'pós-moderno', mas o que seja 'moderno', ou neuzeitlich (em alemão)".

São dois os "pontos iniciais da modernidade", e estes também foram destacados muitas vezes por Flusser fora desse contexto de discussão sobre o pós-moderno. O primeiro é uma sentença do infante Dom Henrique, o Navegador, "vá lá e veja". A sentença se refere à situação antes da segunda globalização, ou seja, da colonização, quando o mar pareceu ser um obstáculo insuperável, intransitável, intransponível. Nesse sentido, a ousadia de arriscar-se nesse empreendimento e descobrir (e conquistar) "novas terras" dá início à nova época da modernidade.

Lembramos que Flusser utiliza a sentença "Navigare necesse, vivere non est necesse", dos navegadores antigos, atribuída ao infante, como mote do seu livro A Escrita modificado para Scribere necesse est, vivere non est (2010b, p. 19). E nas "Imagens técnicas" declara que prefere desistir de viver a desistir de escrever, citando em seguida a mesma frase (1999, p. 33).

A segunda frase é de Nicolau de Cusa, "Deus é onisciente, mas não pode saber melhor que nós que $1+1=2$ ". A frase marca o início do processo de "Emigração dos números do código alfanumérico"111 (FLUSSER, 1991; tradução do autor), ou seja, da cultura baseada em algoritmos. Essa frase sintetiza o que Friedrich Kittler, no seu prefácio da Kommunikologie weiter denken, denomina como "mensagem de Flusser" (Flussers Botschaft): "o número como ele ultrapassa em algoritmos de computadores os limites de nossas línguas"12 (KITTLER, 2009, p. 11; tradução do autor) ${ }^{13}$. Flusser repete que "já no início do Renascimento (em Nicolau de Cusa) as vantagens do pensamento matemático em relação ao pensamento histórico se tornaram evidentes" (1999, p. 50).

Flusser escolhe D. Afonso Henrique (1394-1460) e Cusano (1401-1464), e, notavelmente, não Gutenberg (1400-1468), inventor da impressão; mais uma prova de que Flusser não pode ser reduzido a um teórico da mídia - que daria preferência ao início da Gutenberg-Galaxis, como McLuhan ${ }^{14}$. A ousadia e inovação do infante é, segundo

11 Do alemão: "Die Auswanderung der Zahlen aus dem alphanumerischen Code".

12 Do alemão: "die Zahl, wie sie in Computeralgorithmen die Grenzen unserer Sprachen übersteigt".

13 Sobre "a emigração dos números do código alfanumérico" veja também Flusser (1998b) e Weigel (2006).

14 Confira também Bolz (2008). 
Flusser, "incentivar frota a prosseguir viagem [...] contra um mar que parece estar fervendo", e o de Cusano, "demonstrar a superioridade do pensamento matemático sobre o pensamento articulado em palavras" (1990, p. 1), e nesse comentário encontramos o motivo de Flusser para não escolher Gutenberg. Pensando assim, visto de hoje e da revolução midiática, Gutenberg já foi ultrapassado na hora de entrar em cena, porque é Cusano quem aponta o caminho para o futuro.

\section{Flusser, Lyotard e Rouanet}

Flusser, então, modifica seu conceito de pós-história e entra na discussão contemporânea sobre pós-modernidade. Faz isso inclusive com Sérgio Rouanet, autor do livro As Razões do Iluminismo (1987). Depois de participar de uma mesa-redonda em São Paulo, onde discutiu o projeto "Casa da Cor" e na qual utilizou o conceito, Flusser escreveu o artigo "Justificar o conceito da 'pós-modernidade' (Para Sérgio Rouanet)", rebatendo um argumento do livro dele.

O contexto da "Casa da Cor" ilumina a maneira como Flusser abre o jogo da argumentação com o desaparecimento da dicotomia tradicional entre espaço privado e espaço público. O "significado moderno de 'casa'" - "espaço privado aberto para o espaço público", "praça em cidade industrial", lugar para o engajamento político perdeu sua validade "porque o espaço público (a praça) está desaparecendo sob o peso de canais visíveis e invisíveis" (FLUSSER, [19--?]c, p. 1).

Por isso, Flusser sugere que "casa, no significado pós-moderno, seja um espaço no qual informações adquiridas são armazenadas, processadas e reemitidas rumo a outras casas". Enfim, na discussão em São Paulo, surgiu a objeção de que o conceito "pós-modernidade" articularia uma tentativa de escamotear os problemas não resolvidos pelo projeto moderno, conforme argumento de Rouanet no livro citado. Por conta da sua "discussão com Baudrillard, Lyotard eVirilio" numa outra ocasião, Flusser pretendeu elaborar melhor essas considerações e quis apresentá-las no evento Ars Electronia, de 1988. (FLUSSER, [19--?]c, p. 1). Mais uma vez, o divisor de águas entre a modernidade e a pós-modernidade é o impacto causado pelos canais visíveis e invisíveis na estrutura da sociedade e da cultura, ou seja, a revolução da comunicação.

Todos os problemas, agora, poderiam ser reformulados em equações diferenciais, possibilitando soluções técnicas. $E$, se a razão discursiva é inoperante nas ciências tidas como exatas, todas as suas categorias ficam corroídas: a causalidade (e com ela, a liberdade), inclusive a identidade e a diferença:

Na medida em que o cálculo da probabilidade vai tomando o lugar das explicações causais, na medida em que a futuração vai tomando o lugar da "lei", e na medida em que o acaso vai tomando o lugar da causa, todas as categorias (as imperativas tanto quanto as "puras"), vão ser reformuladas. Pós-modernidade é isto (FLUSSER, [19--c, p. 2). 


\section{Conclusão}

As mudanças estruturais da contemporaneidade baseiam-se na digitalização da informação. Essa inovação encerra um período - aquele da cultura cunhada pela escrita - e abre um futuro, cujas categorias serão alteradas radicalmente para o melhor (espera Flusser), porque a modernidade não cumpriu as promessas, e a pós-modernidade, por sua vez, abre os caminhos.

Michael Manfred Hanke é professor adjunto no Departamento de Línguas e Literaturas Estrangeiras Modernas e professor permanente do Programa de Pós-Graduação em Estudos da Mídia na UFRN.

michaelhankebeaga@yahoo.com.br

\section{Referências}

AYLESWORTH, G. Postmodernism. The Stanford Encyclopedia of Philosophy, 2010. Disponível em: <http://plato.stanford.edu/archives/min2010/entries/postmodernism/>. Acesso em: 4 maio 2011.

BOLZ, N. Am Ende der Gutenberg-Galaxis. Die neuen Kommunikationsverhältnisse. München: Fink, 2008.

FLUSSER, V. Line and Surface. The Philosopher's Index. v. VII, n. 4, p. 1216, 1973.

. Line and Surface. In: Main Currents, 29. Republicado em: Writings, 1973-2002, p. 21-34.

. Carta a Milton Vargas. Berlim: Arquivo Vilém Flusser, 17 de fevereiro de 1974.

. Texto/imagem enquanto dinâmica do Ocidente. Cadernos Rioarte, Ms., p. 6, 1986. (Publicado em Cadernos Rioarte, ano II, n. 5, p. 64-68. Manuscrito Arquivo Flusser, Berlim).

. Pós-História. Vinte instantâneos e um modo de usar. São Paulo, Duas Cidades. Reedição. São Paulo, Annablume: 1982-2011. Prefácio de Rodrigo Duarte, p. 7-18.

. Einige, die "Immateriellen" [sc.: "Les Immatériaux"] betreffende Gedanken. Kulturrevolution, 14, p. 16-19, 1987a.

. Vom Sandwich: eine postmoderne Überlegung. Kulturrevolution, 14, p. 19-21, 1987b.

. A cor no mundo pós-moderno. (Entrevista-vídeo para a Casa da Cor. Robion 03/03/1988). Manuscrito Arquivo Flusser, p. 3, 1988. p. 41-60.

Alphanumerische Gesellschaft. In: Medienkultur. Frankfurt am Main, Fischer, 1989-1999,

. Cultura dos "imateriais"? Revista da Sociedade Brasileira da História da Ciência. Manuscrito publicado como: Zona cinzenta entre ciências, técnica e arte, 3, p. 45-50, 1989.

. Pós-moderno. Para Milton Vargas. Simpósio Internacional Laboratório do Futuro, Steyr, 06/09/1990. Manuscrito Arquivo Flusser, 2 p. 
. Die Auswanderung der Zahlen aus dem alphanumerischen Code. Cultec, Kultur und Technik im 21. Jahrhundert. Das Magazin. Wissenschaftszentrum Nordrhein-Westfalen 2, p. 14-17, 1991a.

Paradigmenwechsel. Vortrag am Prager Goethe-Institut, 1991b.

. Nachgeschichte. Eine korrigierte Geschichtsschreibung. Mannheim: Bollmann, 1993.

Vom Subjekt zum Projekt. Menschwerdung. Mannheim: Bollmann, 1994.

Criação Científica e Artística. In: Ficções Filosóficas. São Paulo, Edusp, 1998a, p. 171-176.

. Êxodo das Cifras. In: Ficções Filosóficas. São Paulo: Edusp, 1998b, p. 187-191.

Ins Universum der technischen Bilder. Göttingen: European Photography, 1999.

. Linha e superfície. In: O mundo codificado. São Paulo: Cosac Naify, 2007, p.101-125.

Contribuição. In: ZIELINSKI, S; FÜRLUS, E. (Orgs.). Arts, Sciences and Technologies in the Arab-Islamic World and Beyond. Köln: Walter König, 2010a, p. 115.

. A Escrita. Há futuro para a escrita? São Paulo: Annablume, 2010 b.

Postmoderne Farben. (Für Gottfried Jäger). Manuscrito não publicado, Arquivo Flusser Berlim, p. 3, [19--?]a.

. Lichtspiele: im wörtlichen und übertragenen Wortsinn. Manuscrito não publicado, Arquivo Flusser Berlim, [19--?]b.

Justificar o conceito da "pós-modernidade". (Para Sérgio Rouanet). Manuscrito não publicado, Arquivo Flusser Berlim, [19--?]c.

. Kitsch e pós-história. (Para Arte em S. Paulo). Manuscrito não publicado, Arquivo Flusser Berlim, [19--?]d.

The photograph as a post-industrial object. (Revised according to suggestions by Leonardo). An essay on the ontological standing of photographs. Manuscrito não publicado, Arquivo Flusser, Berlim, [19--?]e.

KITTLER, F. Vorwort. In: VILÉM, F. Kommunikologie weiter denken. Frankfurt: Fischer, 2009, p. 9-12.

LYOTARD, J-F. La condition postmoderne. Paris: Éditions de Minuit, 1979. (Tradução em alemão: Das postmoderne Wissen. Ein Bericht, 1982. Vienna, Passagen, 2009, 3).

Ob man ohne Körper denken kann. In: GUMBRECHT, H.-U; PFEIFFER, K. L. (orgs.). Materialität der Kommunikation. Frankfurt: Suhrkamp, 1988, p. 813-829.

ROUANET, S. P. As razões do Iluminismo. São Paulo: Companhia das Letras, 1987.

SANTAELLA, L. Flusser na Virada do Milênio. In: BERNARDO, G; MENDES, R. (orgs.): Vilém Flusser no Brasil. Rio de Janeiro: Relume Dumará, 2000. p. 117-130.

STRÖHL, A. Die Geste Mensch. Vilém Flussers Kulturtheorie als kommunikationsphilosophischer Zukunftsentwurf. Marburg, Fachbereich Gesellschaftswissenschaften und Philosophie, PhilippsUniversität Marburg, 2009. Disponível em: <http://archiv.ub.uni-marburg.de/diss/z2009/0786/>. Acesso em: 19 out. 2011.

WEIBEL, P. Les Immatériaux. Jean Francois Lyotards Ausstellung zum postmodernen Zustand der Techno-Welt. Wolkenkratzer-Art-Journal, 8, p. 24-29, 1985.

WEIGEL, S. Die “innere Spannung im alphanumerischen Code" (Flusser). Buchstabe und Zahl in 
grammatologischer und wissenschaftlicher Perspektive. (International Flusser Lectures) Köln: Verlag der Buchhandlung Walther König, 2006.

WELSCH, W. Unsere postmoderne Moderne. 7a. ed. Berlin: Akademie Verlag, 2008.

Artigo recebido em julho e aprovado em outubro de 2014. 